Thorax (1958), 13, 89.

\title{
SELECTIVE ANGIOCARDIOGRAPHY OF THE RIGHT HEART
}

\author{
BY \\ S. HOLESH AND H. M. T. COLES \\ From the Westminster Hospital, London
}

(RECEIVED FOR PUBLICATION JANUARY 26, 1958)

The value of angiocardiography in the investigation of congenital heart disease has been enhanced by the development of the technique of selective injection of the contrast medium through a cardiac catheter. Several Swedish workers have been responsible for many of the important advances in this method, especially the introduction of rapid film exposures in two planes and the delivery of the contrast medium in a short time by means of mechanical pumps. Both these innovations have increased the scope and diagnostic significance of the method.

With the increasing success of surgical correction of defects, precise and accurate anatomical visualization before operation is of great value, even negatively, as it may demonstrate that the lesions are inoperable. The results obtained in 58 cases during the first year of the routine application of selective angiocardiography at Westminster Hospital have shown some pitfalls and complications which are avoidable. With the exception of six adults all the patients were infants or children (see Addendum).

\section{TECHNIQUE}

Selective angiocardiography is best performed in conjunction with formal cardiac catheterization, provided facilities are available for the immediate estimation of oxygen saturations and direct recording of pressures. In this way a provisional diagnosis makes it possible to select the site for injection of the contrast medium and the position of the catheter can be checked by manometry. If the patient is considered unfit for full catheterization but angiocardiography is required before surgery, it is still desirable to have manometry available to make quite sure that the catheter is in the correct chamber.

The largest possible catheter is introduced into the internal saphenous vein in the groin or the median basilic vein in the antecubital fossa. The former is the site of choice in children as it is easier to find a suitable vein and gives more room to the anaesthetist and radiologist.

Catheters smaller than No. 6 Cournand do not, in our experience, give diagnostic results, because the pressure required to inject the contrast medium is too high to be within safe limits and also invariably causes the catheter to recoil from the chamber of choice. Before inserting the catheter we test it for faults by attempting to inject saline through it with the distal end occluded. Leaks from holes or cracks in the plastic material will then become apparent. We have also invariably tested for iodine sensitivity by injecting $\frac{1}{2}-1 \mathrm{ml}$. of contrast medium through the catheter before proceeding with the full injection.

Preliminary films are essential to ensure that the apparatus is working properly and that the correct film densities are obtained. The average exposure has ben 88-96 kV., $400 \mathrm{~mA}$., 0.003-0.01 sec.

For the injection we have used a "gidlund" compressed air pump, which is linked with a two-plane "elema" roll film changer. The pressure selected depends on the internal diameter of the catheter and varies inversely with it. The volume of the injection and the pulse rate of the patient are other determining factors. We have never exceeded $6 \mathrm{~kg}$. per sq. cm., and have found that a considerably lower pressure is sufficient with Lehmann catheters. These have a wider lumen than the Cournand type of the same external diameter. With a No. 7 Lehmann catheter it is practicable to inject by hand.

The maximum speed of the "elema" apparatus used is eight films per second and this was always maintained during the first three seconds in infants. Varying speeds were selected for the later phases of the circulation of the contrast medium. It is important to start the exposure shortly after the injection and particularly so in atrial and ventricular septal defects, because the first passage of contrast medium across the defect takes place almost immediately and is frequently obscured later by filling of other chambers and vessels. Thus if $8 \mathrm{ml}$. of $70 \%$ "diaginol" is required, the exposure should begin after $2 \mathrm{ml}$. has been injected.

The volume of contrast medium used has been calculated on the basis of $1 \mathrm{ml}$. per $\mathrm{kg}$. body weight with a minimum quantity of $5 \mathrm{ml}$. in small infants.

\section{Discussion}

There is no doubt that the selective technique, when correctly applied, increases the diagnostic range and exactitude of angiocardiography. The 
clarity of the examination is increased by the use of a mechanical pump injecting the contrast medium into the selected situation at the correct time, thus avoiding filling of vessels and chambers which are unimportant. This refers in particular to the right atrium, which, in venous angiocardiography, overlies and masks the infundibulum of the right ventricle and the pulmonary valves in the lateral plane. The best position for the catheter tip is therefore in the outflow tract of the right ventricle or the main pulmonary artery. On two occasions we found that injection into one or other main branch of the pulmonary artery caused intense constriction of the pulmonary vessels of the homolateral lung with resultant pooling of the contrast medium throughout the series of exposures, thus reducing the value of the examination. These patients had no untoward symptoms and the complication was only discovered on developing the film.

The selection of the best site for injection depends on the nature of the defects. The right ventricle is most commonly used, particularly for showing pulmonary valvular and infundibular stenosis as well as ventricular septal defects with or without a normal aortic root (Fig. 1). If the catheter is too high in the infundibulum the contrast medium may fail to pass into the left ventricle via a ventricular septal defect if the defect is small. The diagnosis can then only be inferred if subsequently the right ventricle is filled again. With correct positioning of the catheter a ventricular septal defect will be visualized by right-to-left passage of some of the contrast medium in the early phase, regardless of the direction of the shunt, i.e., left to right or right to left (Fig. 2).

In Fallot's tetralogy it is important not to place the catheter tip too high as it may pass into the left ventricular outflow tract or even into the base of the aorta (Figs. 3 and $4 a$ and $b$ ). This will prevent visualization of the infundibulum of the right ventricle, the pulmonary valves and vessels. These are of great importance when contemplating a Blalock-Taussig operation or valvotomy and infundibular resection.

The main pulmonary artery is chosen when one of the following conditions is present, namely, patent ductus arteriosus, aorto-pulmonary fistula, arterio-venous communications in the lungs, anomalous pulmonary veins, and an atrial septal defect with a left-to-right shunt. Moreover, if there is a coarctation of the aorta or aortic stenosis, this position is most satisfactory if left heart catheterization or retrograde aortography cannot be performed (Fig. 5).
When there are combined atrial and ventricular septal defects, injection into the main pulmonary artery should be avoided because it is impossible to decide whether the right ventricle has filled from the atrial or ventricular defect. The catheter should, in such instances, be placed in the right ventricle which will show the ventricular septal defect separately in the first series of films, while later opacification of the right atrium will prove the presence of an atrial septal defect. Major anomalous drainage of the pulmonary veins into the right side of the heart can usually be excluded if the left atrium opacifies before the right atrium.

If there is anomalous pulmonary venous drainage it is desirable to inject into the left and right pulmonary arteries separately. In this way it is possible to determine into which vessel or chamber the anomalous veins are draining (Fig. 6). This is considered a safe procedure provided the contrast medium is injected by hand or mechanically, using a much lower pressure than normally, e.g., $2 \mathrm{~kg}$. per sq. $\mathrm{cm}$. with a No. 7 Lehmann catheter.

The right atrium is rarely used as the site of injection except in atrial septal defects. Most authorities consider that right heart catheterization is dangerous in obstructive tricuspid lesions and some advise injecting the contrast medium into the left ventricle. This is claimed to give a good visual estimate of the size of the right ventricle. In this series we have had no experience of such lesions.

We feel that selective angiocardiography should be performed, when possible, in conjunction with formal cardiac catheterization. In experienced hands the whole procedure can be completed in one hour, thus reducing the screening time and number of anaesthetics. Careful screening in the antero-posterior and lateral planes is essential to ensure that the tip of the catheter is not lying against the ventricular wall. Unfortunately it may assume such a position during the injection, when blobs of contrast medium may be forced between the fibres of the myocardium. This is a potential danger, but, in our experience, small leaks into the myocardium have produced no ill effects and are rapidly absorbed (Fig. 7).

A troublesome complication is recoil of the catheter tip from the selected position during the injection. This, for example, may result in its flipping back from the right ventricle into the right atrium (Fig. 8). In the cases under review we did not use catheters with side openings which certainly reduce the recoil effect. We cannot confirm the view of Kjellberg, Mannheimer, Rudhe, and 


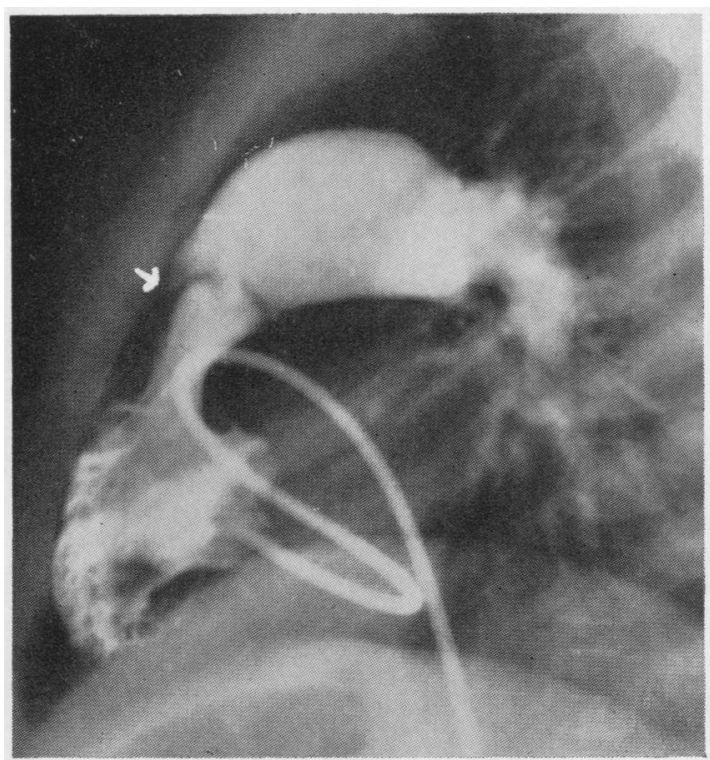

Fig. 1.-C. J., aged 3 years. Valvular pulmonary stenosis showing the "jet sign." Note the translucent areas indicating the site of the thickened valves. Marked post-stenotic dilatation of the main pulmonary artery. The infundibulum of the right ventricle is narrowed.

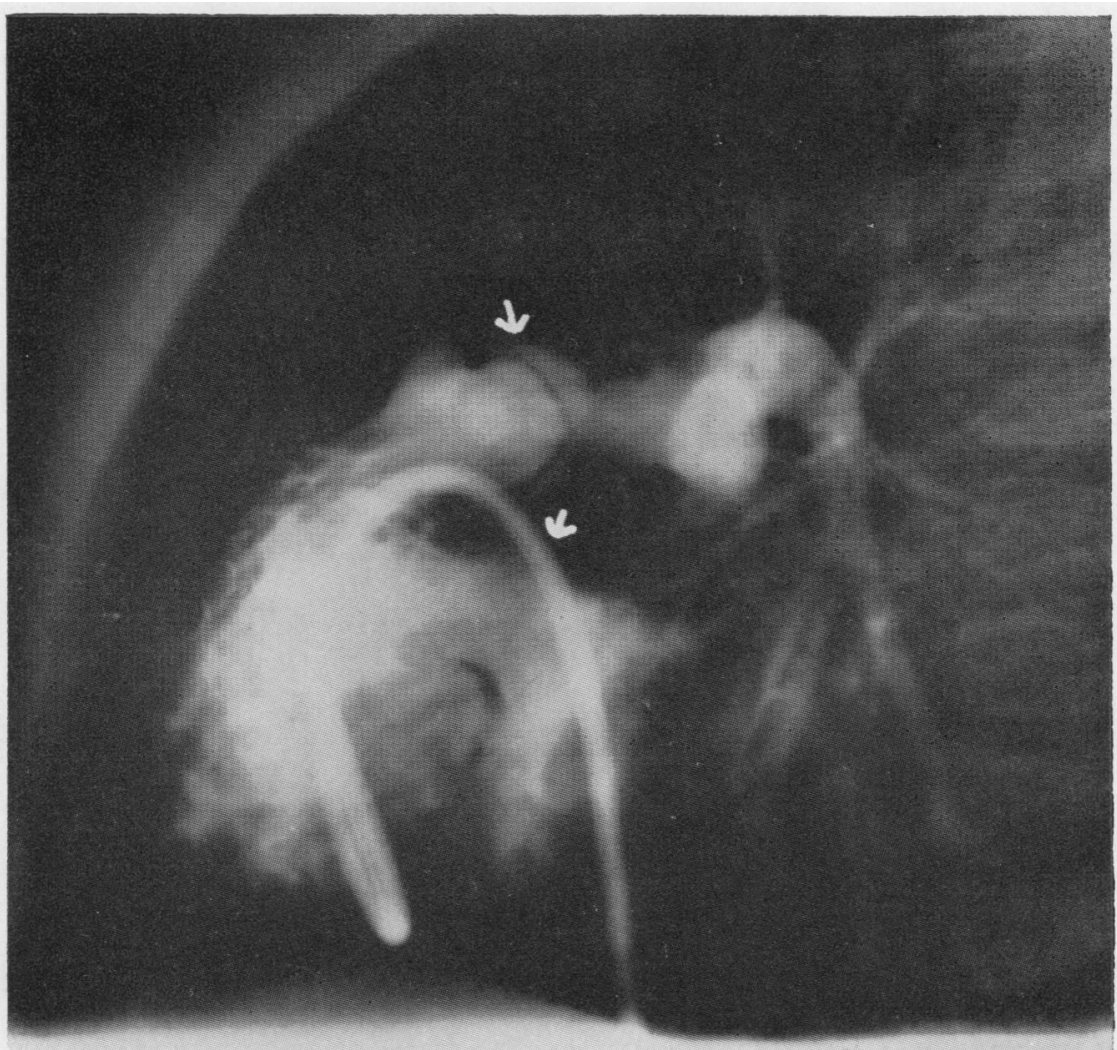

FIG. 2.-W. R., aged 2 years. A ventricular septal defect is demonstrated on the first film after injection of the contrast medium into the right ventricle. There is, in addition, a pulmonary valvular stenosis; the doming of the valves is well shown. 


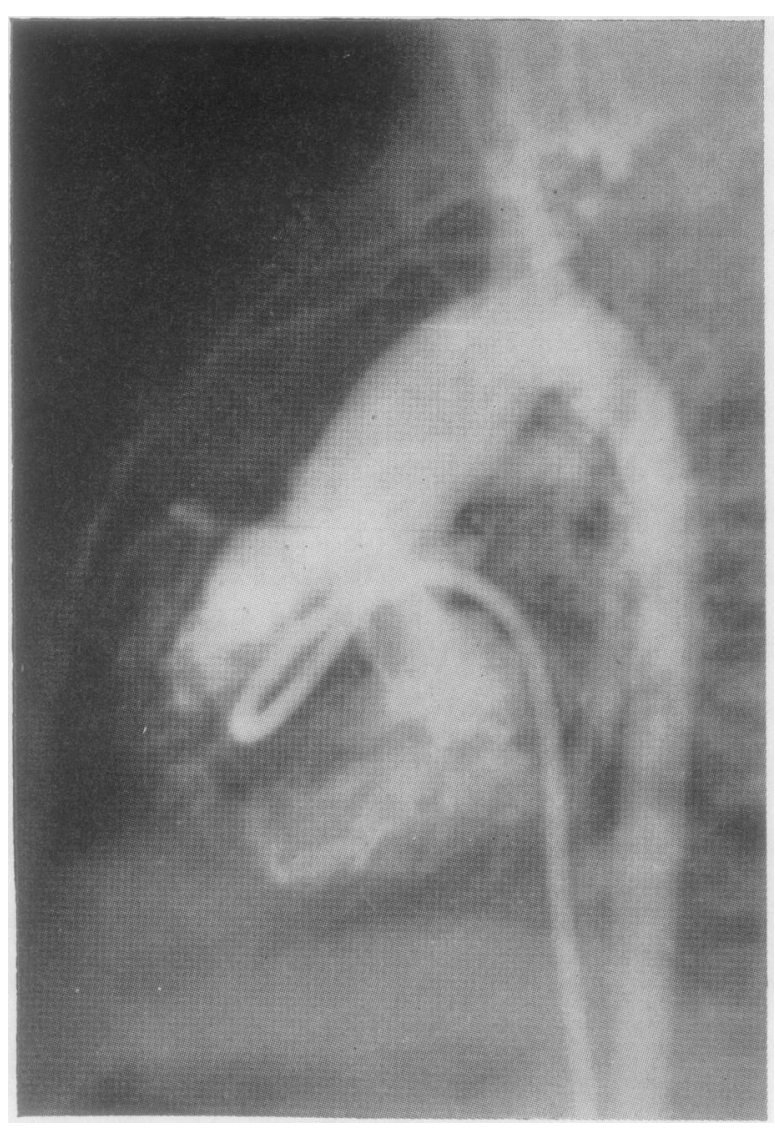

FIG. 3.-J. H., aged 3 months. The catheter has slipped through a ventricular septal defect into the left ventricle and base of the aorta which is over-riding. The main bulk of the contrast medium has entered the aorta and the pulmonary vessels are not clearly visible.

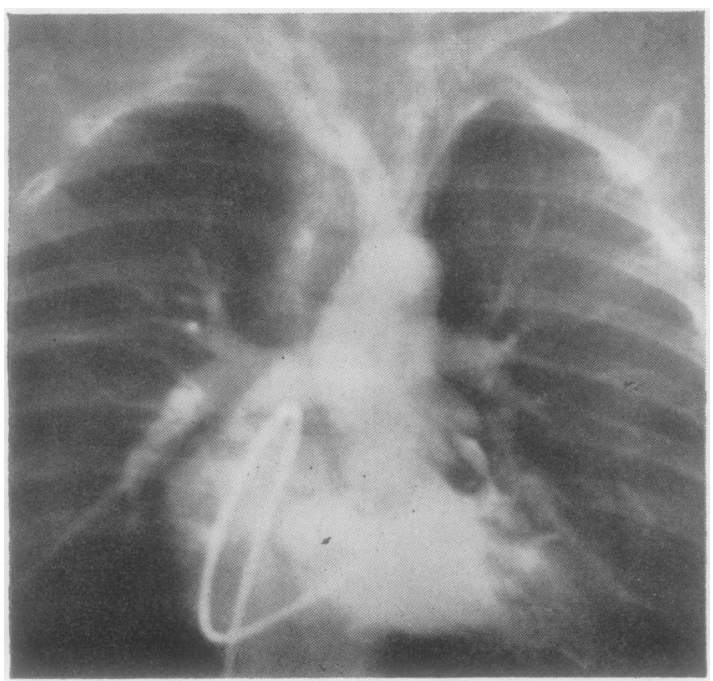

FIG. 4b.-Marked narrowing of the infundibulum and doming of the pulmonary valves. 


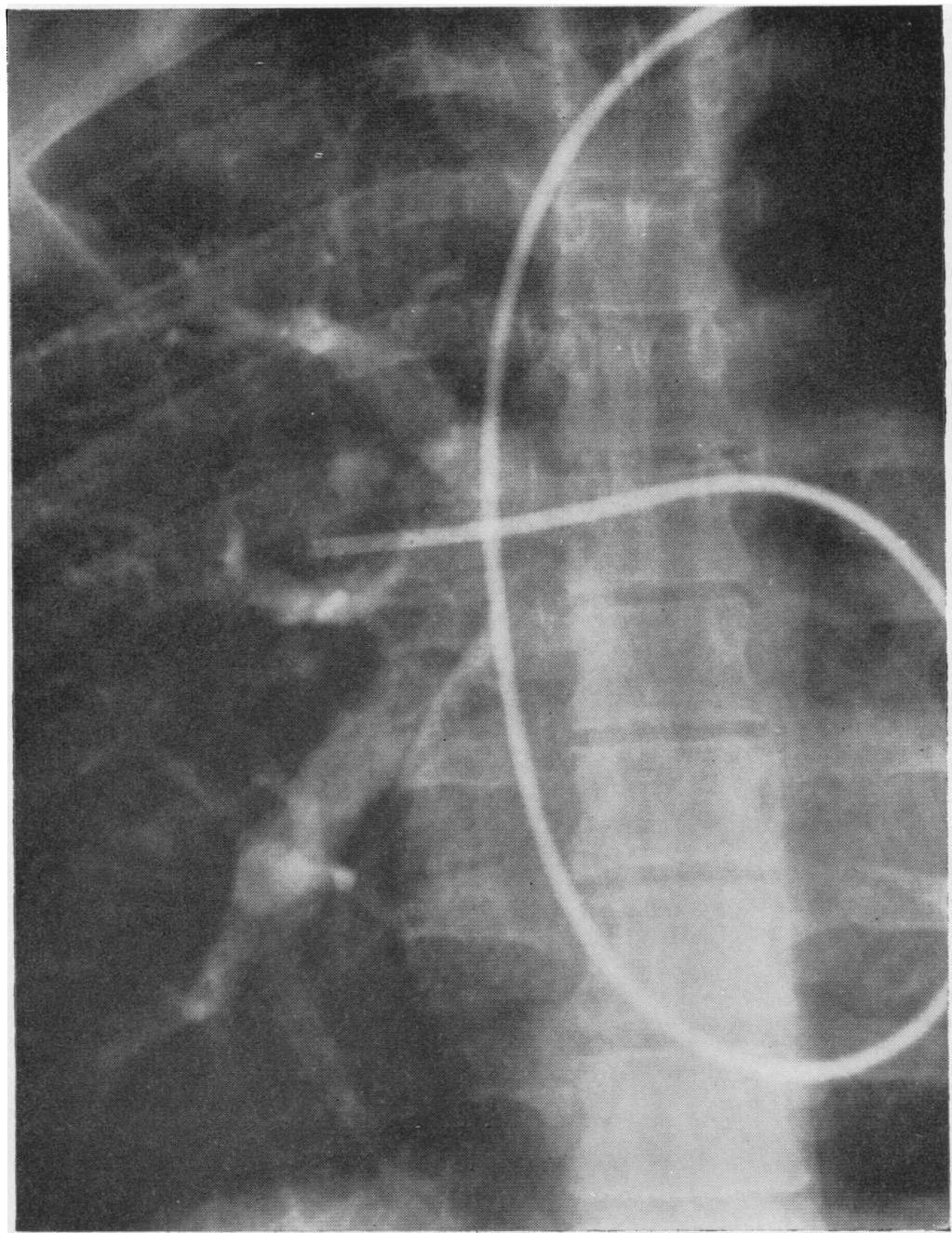

FIG. 6.-M. W., aged 40 years. The right pulmonary veins are draining into the superior vena cava. The contrast medium was injected into the right pulmonary artery. The left pulmonary veins drained into the left auricle.

Jonsson (1955) that recoil is less likely when the catheter makes a wide loop in the right atrium. In 26 cases the catheter was looped in this way and in 10 of these it did not recoil significantly. In the remaining 32 cases in which the catheter was not looped or only slightly kinked, 18 did not recoil. We think that the condition of the catheter is a more important factor; stiff, firm catheters maintain their position better than soft, floppy ones. In addition, Lehmann catheters, requiring lower pressures for injection of the contrast medium, are less liable to recoil than the Cournand variety.

Reflux of contrast medium from the right ventricle into the right atrium may at times occur in the early phase of the examination if the catheter tip is near the tricuspid valve. This we attribute to functional incompetence of the valve due to separation of the cusps by the expansile movement of the catheter during the pressure injection. The reflux is very transitory and never invalidates the series of films. It should not be mistaken for anomalous pulmonary drainage into the right atrium. The reflux is maximal at the time of initial pulmonary arterial filling and before a demonstrable pulmonary venous phase has been reached (Fig. 9).

In some cases where it may be impossible to advance the catheter into the right ventricle it is worth while injecting the contrast medium into 


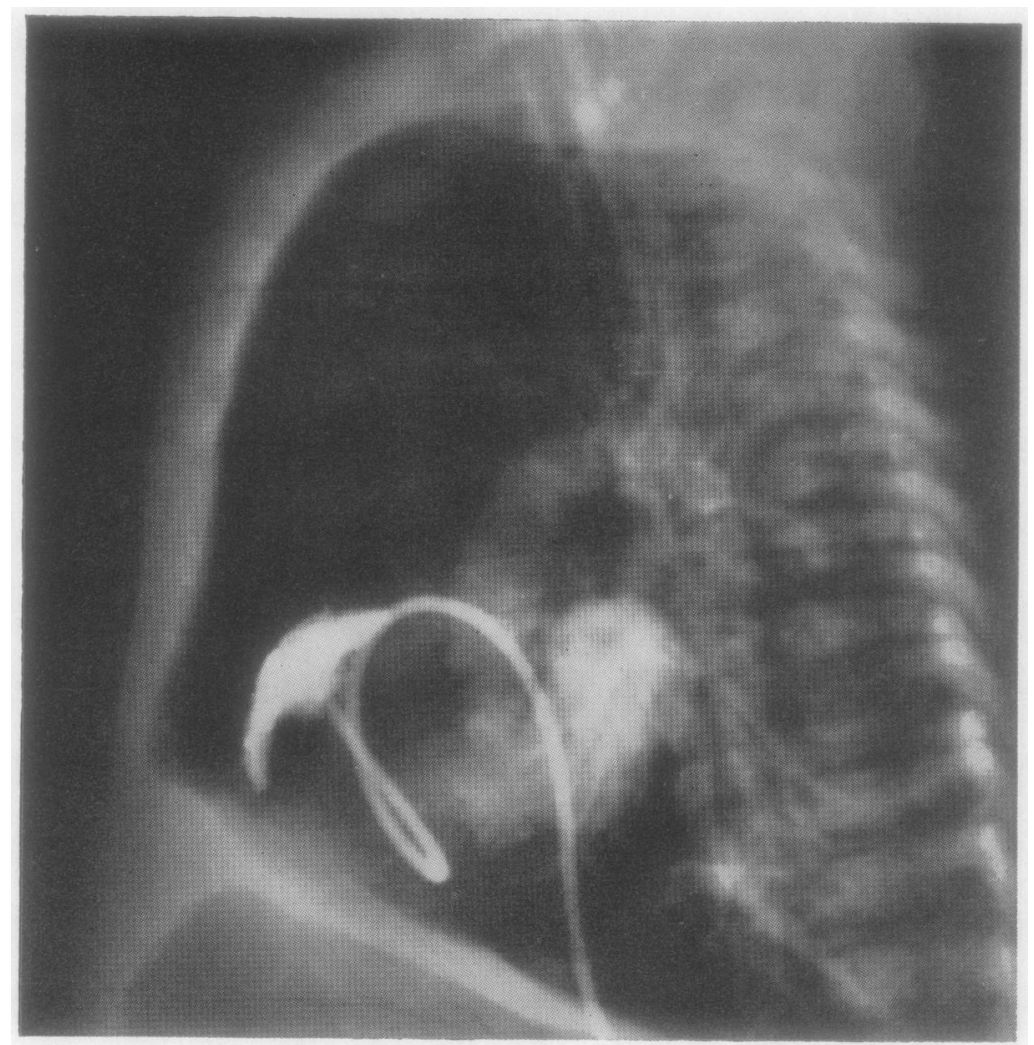

Fig. 7.-S. H., aged 5 weeks. Contrast medium is visible in the myocardium of the right ventricle. The child suffered no ill effects. The aorta is clearly visible jeven though only $5 \mathrm{ml}$. of contrast medium was injected.

the right atrium. In other instances we have made the injection into the azygos vein if the latter is anomalous in origin and prevents entry into the right atrium via the inferior vena cava. This has either been done by hand or mechanically, using a very low pressure. Although the result simulates an ordinary venous angiocardiogram it may still give diagnostic information.

The main value of selective angiocardiography through the right heart is in depicting pulmonary valvular and infundibular stenosis and demonstrating the degree of aortic over-riding and patency of the pulmonary vessels in Fallot's tetralogy. It is also useful in giving a visual impression of the size and site of a ventricular or atrial septal defect. In other complicated cases it may give little more help than a venous angiocardiogram and in fact be impossible to interpret. Even with combined selective angiocardiography and full catheterization it may at times be impossible to arrive at a correct diagnosis, a case of atrial and ventricular septal defect being a good example.

In atrio-ventricularis communis selective angiocardiography gives a confusing picture since, regardless of the site of injection, there is simultaneous filling of all heart chambers (Fig. 10). Cor triloculare bi-atriale may be equally difficult. In one case we diagnosed this anomaly as a large ventricular septal defect on the basis of the catheter findings and a pseudo filling defect in the supposed position of the septum on the first series of films. There appeared to be a separate right ventricular chamber with contrast medium passing from it into the left ventricle via a localized defect. This is contrary to the experience of Rowe, Vlad, and Keith (1956).

\section{SUMmary}

There are many technical causes of failure in selective angiocardiography. Mechanical failure 


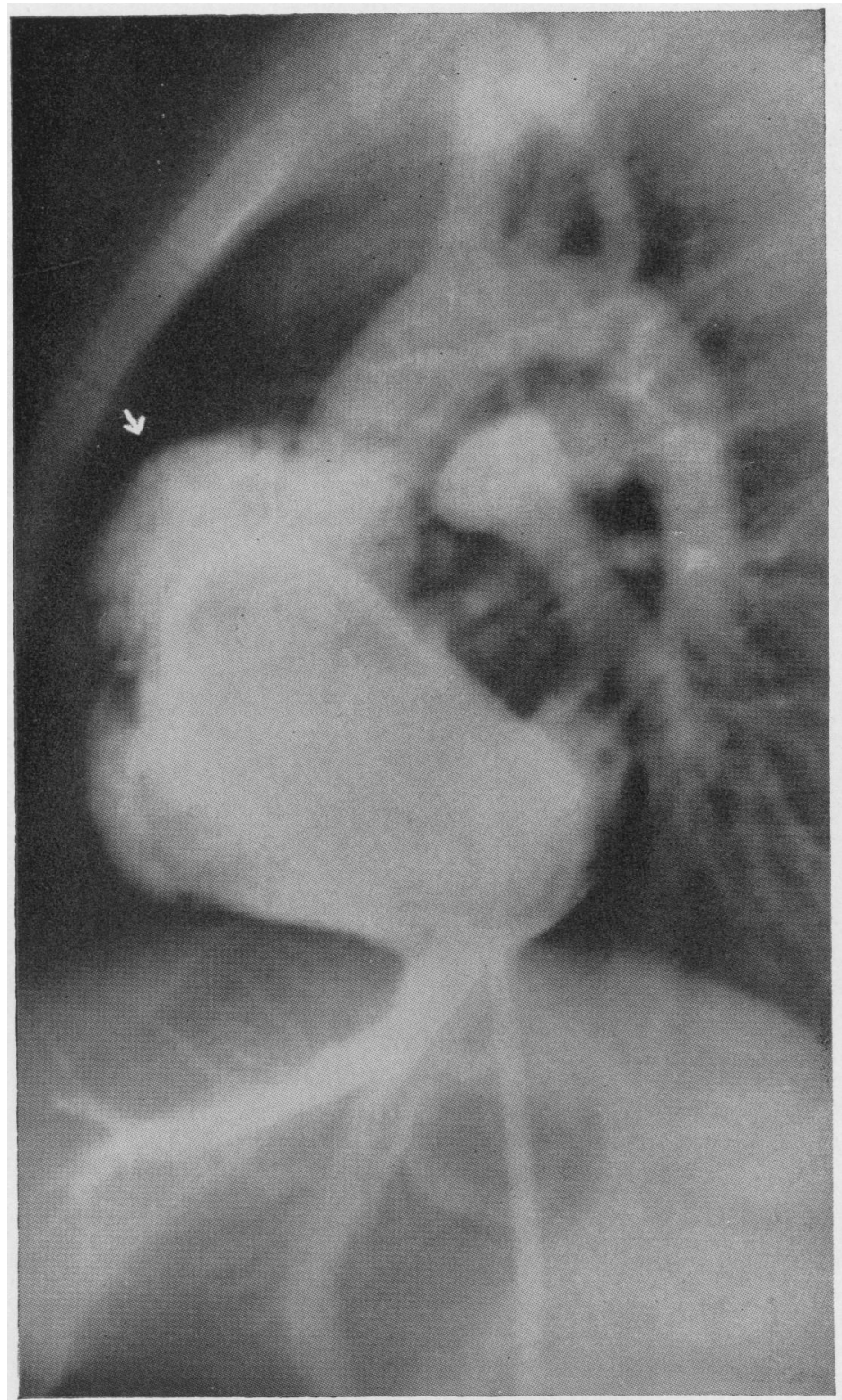

FIG. 8.-P. W., aged 1 year. Fallot's tetralogy. The catheter has recoiled into the right auricle. The auricular appendage is obscuring the detail of the infundibulum of the right ventricle and the over-riding aorta prevents visualization of the pulmonary valves.

of the $x$-ray equipment or pump should be eliminated so far as possible by routine testing of the apparatus before each examination. Similarly, faults in the catheter will be detected if it is tested in the way we have described. The risk of the end of the catheter recoiling during the injection can be minimized by using only stiff, resilient catheters, preferably with side openings near the tip. The proper selection of the site for injection is probably the most important factor, and this can only be decided in the majority of cases following full catheterization. The 58 selective angiocardiograms we have reviewed were obtained in the first year of using an "elema" two-plane $x$-ray apparatus and thus represent the results of a process of trial and error with this technique. 


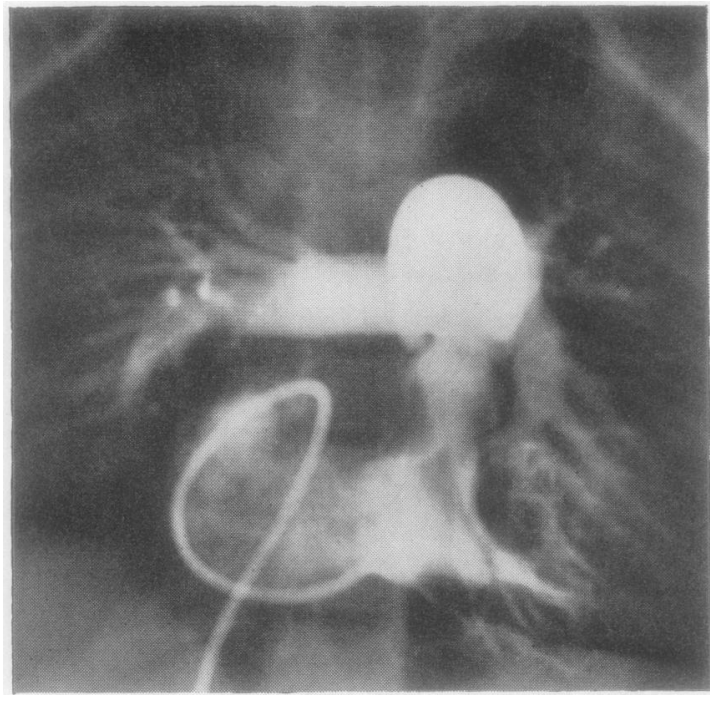

FIG. 9

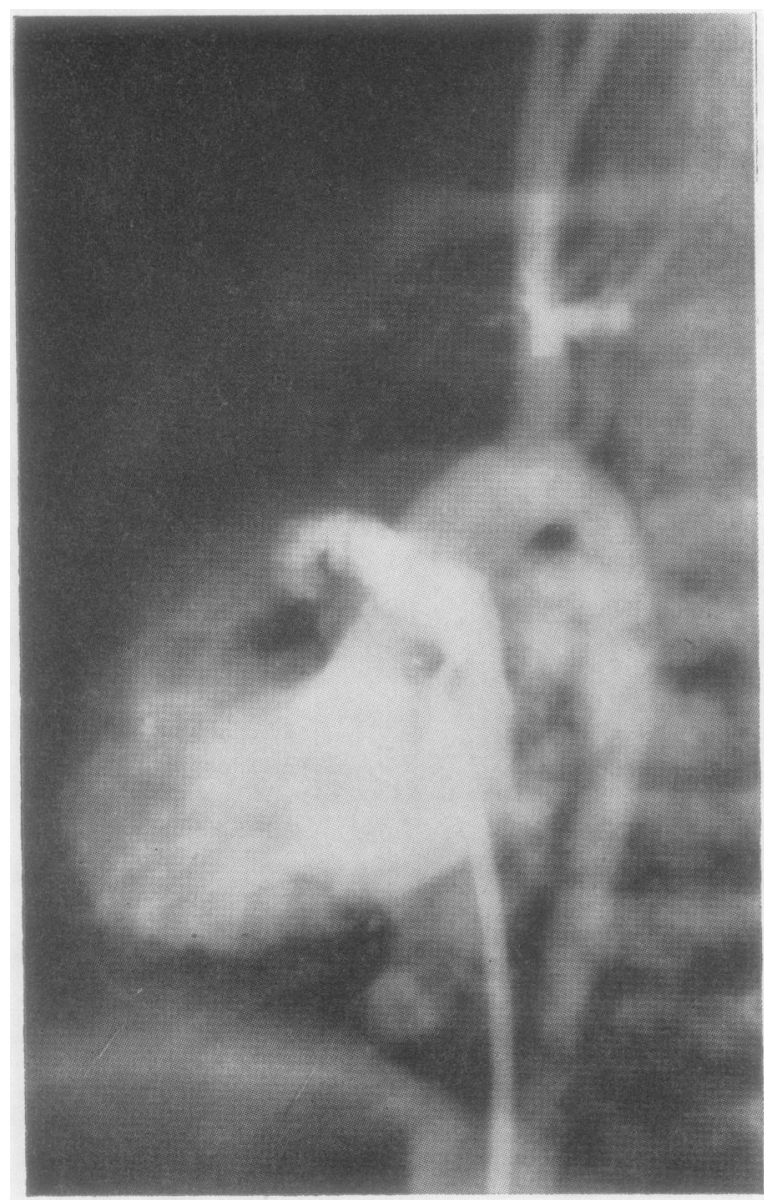

Fig 10
FIG. 9.-C. J., aged 3 years. Reflux into the right auricle during the first second after the injection. There is a pulmonary valvular stenosis and post-stenotic dilatation of the pulmonary artery (same case as Fig. 1).

FIG. 10.-S. I., aged 11 weeks. Atrio-ventricularis communis. All the cardiac chambers are filled in addition to the aorta and pulmonary vessels. The injection of contrast medium was into the left auricle. The appendage of the latter is overlying the base of the aorta.

We are indebted to Dr. I. M. Anderson and Dr. Peter Kerley for their advice and constructive criticism, and to Mr. Charles Drew, Dr. C. J. Gavey, and Dr. A. Leatham for permission to publish their cases. We should also like to thank Miss K. C. Clark and her staff for the care they took with the reproductions.

\section{REFERENCES}

Kjellberg, S. R., Mannheimer, E., Rudhe, U., and Jonsson, B. (1955). Diagnosis of Congenital Heart Disease. The Year Book Publishers, Chicago.

Rowe, R. D., Vlad, P., and Keith, J. D. (1956). Radiology, 66, 344

\section{ADDENDUM}

The patients examined were aged as follows:

\begin{tabular}{|c|c|c|}
\hline \multicolumn{2}{|l|}{ Age of Patients } & No. Examined \\
\hline $\begin{array}{l}2 \text { weeks }-1 \text { year } \\
1 \text { year }-5 \text { years } \\
5 \text { years }-10,, \\
10 \text {," } 15 \text {, } \\
\text { Over } 15 \text { years }, .\end{array}$ & $\begin{array}{l:}\ldots \\
\ldots \\
\ldots \\
\ldots \\
\ldots\end{array}$ & $\begin{array}{r}18 \\
23 \\
9 \\
2 \\
6\end{array}$ \\
\hline Total & $\ldots$ & 58 \\
\hline
\end{tabular}

The conditions diagnosed were as follows :

Fallot's tetralogy

Pulmonary stenosis and ventricular septal defoct with normal aortic root

Ventricular septal defect

Anomalous pulmonary venous drainage

Pulmonary stenosis (including one with atrial septa defect and one with patent ductus arteriosus).

Truncus arteriosus

Atrial septal defect

Coarctation of the aorta

Mitral stenosis

No abnormality detected

Atrial and ventricular septal defects

Atrio-ventricularis communis

Ventricular septal defect and mitral stenosis

(wiosus "with arterio-venous anomaly in the right upper lobe)

Coarctation of the aorta and mitral stenosis , , aorta, atrial septal defect, and partial anomalous pulmonary venous drainage

\section{Cor triloculare bi-atrium}

Cof triloculare bi-atrium a

Left coronary arterio-ve

Miscellaneous :

Agenesis of right lung

Arterio-venous anomalies of both lungs

Bilateral obstructive emphysema

Unsatisfactory 